\title{
EXISTENCE OF TRIPLE POSITIVE SOLUTIONS FOR A THIRD ORDER GENERALIZED RIGHT FOCAL PROBLEM
}

\author{
Zhanbing BAi AND XiAngli Fei
}

Abstract. We obtain sufficient conditions for the existence of at least three positive solutions for the third-order three-point generalized right focal boundary value problem

$$
\begin{gathered}
x^{\prime \prime \prime}=q(t) f\left(t, x, x^{\prime}, x^{\prime \prime}\right), t_{1} \leqslant t \leqslant t_{3}, \\
x\left(t_{1}\right)=x^{\prime}\left(t_{2}\right)=0, \eta x\left(t_{3}\right)+\delta x^{\prime \prime}\left(t_{3}\right)=0,
\end{gathered}
$$

where $f:\left[t_{1}, t_{3}\right] \times[0, \infty) \times R^{2} \rightarrow[0, \infty), q:\left(t_{1}, t_{3}\right) \rightarrow[0,+\infty)$ are nonnegative continuous functions, $\delta>0, \eta \geqslant 0$ are constants. This is an application of a new fixed-point theorem introduced by Avery and Peterson [6].

Mathematics subject classification (2000): 34B15.

Key words and phrases: triple positive solutions, focal boundary value problem, fixed-point theorem.

\section{REFERENCES}

[1] R. P. Agarwal, Focal Boundary Value Problems for Differential and Difference Equations, Kluwer Academic, Boston, 1998.

[2] R. P. Agarwal, D. O'Regan, and P. J. Y. Wong, Positive Solutions of Differential, Difference, and Integral Equations, Kluwer Academic Publishers, Boston, 1999.

[3] D. R. ANDERSON, Green's function for a third-order generalized right focal problem, J. Math. Anal. Appl., 288, (2003) 1-14.

[4] D. R. ANDERSON, J. M. DAVIS, Multiple solutions and eigenvalues for third order right focal boundary value problems, J. Math. Anal. Appl., 267, (2002) 135-157.

[5] R. I. AVERY, A generalization of the Leggett-Williams fixed point theorem, Math. Sci. Res. Hot-line, 2, (1998) 9-14.

[6] R. I. AVERY, A. C. PEterson, Three positive fixed points of nonlinear operators on ordered Banach spaces, Comput. Math. Appl., 42, (2001) 313-322.

[7] Z. B. BAI, Y. F. WANG AND W. G. GE, Triple positive solutions for a class of two-point boundary-value problems, Electron. J. Differential Equations, 2004, (6) (2004), 1-8.

[8] D. Guo, V. Lakshmikantham, Nonlinear Problems in Abstract Cones, Academic Press, New York, 1988.

[9] R. W. LEGGETT, L.R. WiLliams, Multiple positive fixed points of nonlinear operators on ordered Banach spaces, Indiana Univ. Math. J., 28, (1979) 673-688.

[10] M. A. KRASNOSEL'SKII, Positive Solutions of Operator Equations, Noordhoff, Gronignen, 1964.

[11] E. ZEIDLER, Nonlinear Analysis and Its Applications I: Fixed-Point Theorems, Springer-Verlag, New York, (1993). 